\title{
Chronic pain profile: An interaction between biological and psychosocial factors
}

\author{
Marcus A. Alcântara ${ }^{1,2}$, Rosana F. Sampaio ${ }^{3 \#}$, Mariana A. P. Souza ${ }^{2}$, Fabiana C. M. Silva ${ }^{4}$, \\ Renata N. Kirkwood ${ }^{5}$ \\ ${ }^{1}$ Department of Physical Therapy, Universidade Federal dos Vales do Jequitinhonha e Mucuri (UFVJM), Diamantina, Brazil \\ ${ }^{2}$ Post Graduate Program in Rehabilitation Sciences, Universidade Federal de Minas Gerais (UFMG), Belo Horizonte, Brazil \\ ${ }^{3}$ Department of Physical Therapy, Universidade Federal de Minas Gerais (UFMG), Belo Horizonte, Brazil; \\ ${ }^{\#}$ Corresponding Author: rosana.sampaio@pq.cnpq.br \\ ${ }^{4}$ Department of Occupational Therapy, Institute of Health Sciences, Universidade Federal do Triângulo Mineiro (UFTM), Uberaba, \\ Brazil \\ ${ }^{5}$ Kinesiology Department, University of Waterloo, Waterloo, Canada
}

Received 12 May 2013; revised 18 June 2013; accepted 5 July 2013

Copyright (C) 2013 Marcus A. Alcântara et al. This is an open access article distributed under the Creative Commons Attribution License, which permits unrestricted use, distribution, and reproduction in any medium, provided the original work is properly cited.

\section{ABSTRACT}

OBJECTIVE: To Identify subgroups of workers with chronic pain based on the interaction of different pain dimensions (sensory, affective, evaluative and mixed), depression, beliefs regarding pain, physical incapacity and sociodemographic-clinical data. METHODS: An observational cross-sectional study was carried out with a convenience sample made up of 115 patients with work-related musculoskeletal disorders (WRMD). The participants answered the McGill Pain Questionnaire, Beck Depression Inventory, Survey of Pain Attitudes, RolandMorris Disability Questionnaire and a form for socio-demographic and clinical data. RESULTS: Four distinct subgroups were identified, two of which reported pain of a sensory-affective nature and two reported predominantly sensory pain. The individuals in subgroups I and III reported higher levels for all variables analyzed, while the first cluster had the highest mean scores. The subgroup II exhibited moderate degrees of physical disability and a high sick leave index, although the members of this group were less depressed and less dependent upon anal-

\footnotetext{
*Conflict of interest statement: The authors declare that they have no competing interests.

Authors' contributions: All authors collaborated in designing the study. MAA e RFS were responsible for conception and design. RFS was responsible for the coordination of the study. MAA collected the data. MAA, MAPS and FCMS wrote the manuscript. FCMS and RNK were responsible for drafting the article. All authors read and approved the final manuscript.
}

gesics. Lower levels of pain, physical disability and depression were associated to subgroup IV, which also had the greatest proportion of males. Beliefs were similar among the subgroups. CONCLUSIONS: Patients with moderate to strong chronic pain associated to sensory and affective components exhibited a higher degree of disability and depression. The results suggest that the chronification process of pain and its functional consequences vary between individuals and are influenced by emotional factors.

Keywords: Disability Evaluation; Functioning, Chronic Pain; Musculoskeletal Diseases;

Depression

\section{INTRODUCTION}

Chronic pain is an important health problem to be studied because of its high prevalence and negative impact on physical, psychological and social functions [1-3]. Chronic pain has been defined as pain which persists even after the tissue damage that triggered its onset has been resolved [4]. Studies that investigated workers with work-related musculoskeletal disorders (WRMD) found that the prevalence of chronic pain is estimated to be between $30 \%$ and $60 \%$, affecting a large portion of individuals within the economically active age range [1-3]. Chronic pain is associated with diverse health conditions and is an important predictor of functional limitation [5]. There is evidence that chronic pain is associated with anxiety, depression, poor quality of sleep and a reduced capacity to perform daily and occupational activities and 
that it also impairs participation in social activities [1, 4-9].

The importance of addressing chronic pain as a multidimensional phenomenon has been stressed, along with the need to consider the interrelation between biological aspects, psychological factors and social context in order to understand an individual's perception of pain and illness [10-12]. There is evidence to suggest that the interaction between chronic pain and negative emotional factors triggers psychological effects and reciprocal behavioral in the illness process, influencing the expression and adaptation of individuals with regard to the chronification of pain [10] and [13]. Burns et al. [14] state that feelings and expectations regarding the meaning of pain affect the relationship between pain and psychological factors.

In order to gain a better understanding of the association between pain and psychosocial factors, researchers have turned to studies on the profile of patients with chronic pain. Turk and Okifuji [15] and Alcântara et al. [16] report the existence of subgroups of patients based on psychosocial characteristics, regardless of health status. Turk [17] later reaffirmed the importance of assessing the profile of these individuals in an attempt to comprehend why some people get better with treatment and others do not. More recently, Corbière et al. [18] and Gironda and Clark [19] found that patients with moderate to severe depression and high levels of affective pain (as assessed using the McGill Pain Questionnaire) were less likely to return to work.

The first aim of the present study was to establish subgroups of workers withWRMD. Thesecond aim was to determinewhether these subgroups are different in terms of biological, psychosocial, socio-demographic and clinical factors.

\section{METHOD}

\subsection{Design}

An observational, cross-sectional study was carried out based on a sample of workers with chronic pain. The participants were recruited from the Worker Health Reference Center [Centro de Referência em Saúde do Trabalhador] in the city of Belo Horizonte, Minas Gerais, Brazil. Eligible workers who agreed to participate in the study on the day they visited their physician or physiotherapist. After signing a consent term, the workers responded to questions about pain, and biological, psychosocial, socio-demographics and clinical factors. The study received approval from the Ethics Committee of the Universidade Federal de Minas Gerais (Brazil).

\subsection{Participants}

To participate in the study, workers needed to be 18 years of age or older and pain with duration of more than six months since the onset of the symptoms [20]. In addition, the workers should have a clinical diagnosis of WRMD. In Brazilian legislation, WRMD is defined as a work-related syndrome characterized by the occurrence of various concomitant or non-concomitant symptoms, such as pain, paresthesia, sensation of weight on the limb and fatigue [21]. There was no restriction with regard to gender. Workers with difficulties in answering the questionnaires and those with associated pathologies, such as neurological problems, were excluded.

\subsection{Measurement of Pain}

Pain experience was measured byMPQ Brazilian version (Br-MPQ) [22] which has been described in the literature as having adequate psychometric properties [23]. The instrument evaluates the sensory, affective, evaluative and mixed dimensions of pain. The interpretation of the responses was performed by the Number of Words Chosen, Pain Rating Index and Present Pain Intensity scale.

\subsection{Measurement of Biological Factors}

\section{Physical Disability}

Physical disability was measured using the RolandMorris Disability Questionnaire (RMDQ), which consists of 24 statements for which the participants are instructed to respond affirmatively to each statement that applies to them. Recent studies report that the RMDQ has adequate psychometric properties as well as good validity and reliability in diverse chronic health conditions [24]. The Brazilian version (Br-RMDQ) was used in the present study [25]. The location of the pain at the end of the phrase "because of my back" was replaced with the location in which the participant reported feeling pain, for example, "because of my shoulder pain".

\subsection{Measurement of Psychosocial Factors}

\subsubsection{Depression}

Depression was measured with the Portuguese version of the Beck Depression Inventory (BDI) [26]. This scale consists of 21 items scored on a four-point Likert scale $(0$ to 3), with higher scores denoting a worse depressive state. The BDI is described as having adequate psychometric properties and 20 points is the cutoff point for indicating depression [26].

\subsubsection{Pain Beliefs}

The brief version of the Survey of Pain Attitudes (SOPA-brief) adapted for Portuguese was used and consists of 30 items distributed among seven subscales addressing pain beliefs: Pain Control, Emotion, Disability, 
Harm, Medication, Solicitude and Medical Cure. The scale has adequate psychometric properties [27]. The responses are scored on a five-point Likert scale that indicates to what extent the respondent agrees with each item, ranging from 0 (completely false) to 4 (completely true). Higher scores on each subscale denote that the participant's belief is more adaptive. Inversely, the Control and Emotion subscales have an inverse orientation to the others.

\subsection{Measurement of Socio-Demographics and Clinical Data}

A protocol designed for the present study was used. The following aspects were addressed: socio-demographic variables (i.e., gender, age and marital status), socioeconomic variables (i.e., schooling, occupation, income, current work status and reception of benefits) and clinical variables (i.e., medical diagnosis, occupational nexus, side of the body affected, time elapsed since the onset of symptoms).

\subsection{Data Analysis}

The data are presented descriptively. Cluster analysis was used to identify natural groups of individuals with similar pain profiles regarding the dimensions of the Br-MPQ [28]. A hierarchical clustering procedure was performed, in which small groups were united two-bytwo to form progressively larger groups until reaching a specific stopping point or arriving at a single group [29]. The procedures for the cluster analysis involved three stages, which are described below:

In the first stage, the scores of the sensory, affective, evaluative and mixed subscales of the Br-MPQ were standardized, as the number of points on each response scale varies. Standardization ( $Z$ scores) of all items was performed on a scale from 1 to 4 , thereby allowing the comparison of responses among the different items.

In Stage 2, the squared Euclidean distance was used to broaden the differences between individuals in different clusters. Ward's method was used to minimize the internal variance and maximize the external variance of the clusters. A cutoff line occurs when the total sum of the squares increases more quickly, with a greater "leap" between these values [30]. The choice of the cutoff line is subjective, even when using the previously described criteria. The eta-squared measure was used to calculate the percentage of variance explained by the sensory, affective, evaluative and mixed dimensions of the Br-MPQ based on differences between groups. Significant differences between groups were defined by analysis of variance.

Stage 3 consisted of the characterization of the sociodemographic data, clinical data, pain beliefs (SOPA- brief), physical disability (Br-RMDQ) and depression (BDI) in relation to the different clusters. The Student's t-test for independent samples was used to determine associations between the continuous variables and each cluster. The $\mathrm{Z}$ test was used for the categorical variables. Stages 1 and 2 were performed on the Microsoft Excel 4.0 program for Windows. The Statistical Package for the Social Sciences (version 13.0) was used for the bivariate analyses, considering alpha $=5 \%$.

\section{RESULTS}

\subsection{Flow of Participants through the Study}

A convenience sample made up of 115 workers with chronic pain participated of the study. Mean duration of pain was five years [standard deviation $(\mathrm{SD})=3.5$ years]. Mean age was 42 years $(\mathrm{SD}=9.52$; range $=19$ to 60 years). The sample was predominantly female (87\%), with schooling corresponding to an elementary education and an average monthly salary of U\$280. Most the workers were from the service sector $(56 \%)$ followed the industrial sector $(26 \%)$.

\subsection{Can the MPQ Dimensions Establish Subgroups of Workers with WRMD?}

The hypothesis that the MPQ dimensions could to make subgroups of workers with WRMD was confirmed. The cluster analysis revealed accentuated growth in the dissimilarity between subgroups between Steps 111 and 112, suggesting an ideal solution with four clusters. The standardized scores of the pain profile in each cluster are displayed in detail in Table 1. The eta-squared measure revealed that the subgroups differed mainly with regard to the evaluative (0.86) and affective (0.46) dimensions, whereas the sensory $(0.13)$ and mixed $(0.19)$ dimensions were less effective at differentiating the groups. Analysis of variance revealed significant differences between groups on each subscale of the Br-MPQ $(\mathrm{p}<0.05)$, demonstrating that the cluster analysis procedures for grouping similar profiles were successful.

Are these subgroups delineated in terms of biological, psychosocial and socio-demographics and clinical factors?

1) Biological Factors

a) Pain

Subgroups I and III showed the highest levels for the PRI and NWC (Table 2). The scores were significantly higher in comparison to the subgroups two and four $(\mathrm{p}<$ 0.05). Regarding the PPI, the participants reported varied pain levels, with no significant differences between subgroups (Table 2). On average, pain was moderate in the four subgroups at the time of the interview.

b) Physical disability

The results suggest a tendency of the individuals in the 
Table 1. Mean (SD) of the multidimensional assessment of pain (McGill Pain Questionnaire) after standardization of scores for each subgroup and mean difference (95\% CI) between subgroups.

\begin{tabular}{|c|c|c|c|c|c|c|c|c|c|c|}
\hline \multirow{2}{*}{$\begin{array}{c}\text { Br-MPQ } \\
\text { Dimensions } \\
(0-4)\end{array}$} & \multicolumn{4}{|c|}{ Subgroups } & \multicolumn{6}{|c|}{ Difference between the Subgroups } \\
\hline & $\begin{array}{c}1 \\
\mathrm{n}=52 \\
(46 \%)\end{array}$ & $\begin{array}{c}2 \\
\mathrm{n}=13 \\
(11 \%)\end{array}$ & $\begin{array}{c}3 \\
\mathrm{n}=23 \\
(20 \%)\end{array}$ & $\begin{array}{c}4 \\
n=27 \\
(23 \%)\end{array}$ & $1-2$ & $1-3$ & $1-4$ & $2-3$ & $2-4$ & $3-4$ \\
\hline Sensory & $2.56(0.35)$ & $2.18(0.28)$ & $2.57(0.37)$ & $2.42(0.28)$ & $\begin{array}{c}0.38(0.17 \\
\text { to } 0.59)\end{array}$ & $\begin{array}{c}-0.01(-0.18 \\
\text { to } 0.16)\end{array}$ & $\begin{array}{c}0.14(-0.02 \\
\text { to } 0.30)\end{array}$ & $\begin{array}{c}-0.39(-0.63 \\
\text { to }-0.15)\end{array}$ & $\begin{array}{c}-0.24(-0.43 \\
\text { to }-0.05)\end{array}$ & $\begin{array}{c}0.15(-0.04 \\
\text { to } 0.34)\end{array}$ \\
\hline Affective & $2.64(0.55)$ & $1.70(0.45)$ & $2.48(0.29)$ & $1.75(0.30)$ & $\begin{array}{c}0.94(0.61 \\
\text { to } 1.27)\end{array}$ & $\begin{array}{l}0.16(-0.08 \\
\text { to } 0.40)\end{array}$ & $\begin{array}{c}0.89(0.66 \\
\text { to } 1.12)\end{array}$ & $\begin{array}{c}-0.78(-1.03 \\
\text { to }-0.53)\end{array}$ & $\begin{array}{l}-0.05(-0.29 \\
\quad \text { to } 0.19)\end{array}$ & $\begin{array}{c}0.73(0.56 \\
\text { to } 0.90)\end{array}$ \\
\hline Evaluative & $3.37(0.48)$ & $1.75(0.00)$ & $1.75(0.00)$ & $1.69(0.20)$ & $\begin{array}{c}1.62(1.35 \\
\text { to } 1.89)\end{array}$ & $\begin{array}{c}1.68(0.61 \\
\text { to } 1.27)\end{array}$ & $\begin{array}{c}1.68(1.47 \\
\text { to } 1.89)\end{array}$ & $0.00(0.00)$ & $\begin{array}{c}0.06(-0.05 \\
\text { to } 0.17)\end{array}$ & $\begin{array}{c}0.06(-0.02 \\
\text { to } 0.14)\end{array}$ \\
\hline Mixed & $2.30(0.49)$ & $2.29(0.48)$ & $2.09(0.37)$ & $1.81(0.33)$ & $\begin{array}{c}0.01(-0.29 \\
\text { to } 0.31)\end{array}$ & $\begin{array}{c}0.21(-0.02 \\
\text { to } 0.44)\end{array}$ & $\begin{array}{c}0.49(0.28 \\
\text { to } 0.70)\end{array}$ & $\begin{array}{c}0.20(-0.09 \\
\text { to } 0.49)\end{array}$ & $\begin{array}{c}0.48(0.22 \\
\text { to } 0.74)\end{array}$ & $\begin{array}{c}0.28(0.08 \\
\text { to } 0.48)\end{array}$ \\
\hline
\end{tabular}

Values in bold presented $\mathrm{p}<0.05$.

Table 2. Mean (SD) of the Pain Rating Index (PPI), Number of Words Chosen (NWC), Present Pain Intensity (PPI), physical disability, depression and pain beliefs factors for each subgroup and mean difference $(95 \% \mathrm{CI})$ between subgroups.

\begin{tabular}{|c|c|c|c|c|c|c|c|c|c|c|}
\hline \multirow[b]{2}{*}{ Factors } & \multicolumn{4}{|c|}{ Subgroups } & \multicolumn{6}{|c|}{ Difference between the Subgroups } \\
\hline & $\begin{array}{c}1 \\
\mathrm{n}=52 \\
(46 \%)\end{array}$ & $\begin{array}{c}2 \\
\mathrm{n}=13 \\
(11 \%)\end{array}$ & $\begin{array}{c}3 \\
\mathrm{n}=23 \\
(20 \%)\end{array}$ & $\begin{array}{c}4 \\
\mathrm{n}=27 \\
(23 \%)\end{array}$ & $1-2$ & $1-3$ & $1-4$ & $2-3$ & $2-4$ & $3-4$ \\
\hline \multicolumn{11}{|l|}{$\begin{array}{c}\text { Pain } \\
\text { Assessment }\end{array}$} \\
\hline PRI (0 - 68) & $39.54(8.54)$ & $27.31(7.25)$ & $35.87(6.38)$ & $28.70(5.75)$ & $\begin{array}{c}12.23(7.08 \\
\text { to } 17.38)\end{array}$ & $\begin{array}{c}3.67(-0.30 \\
\text { to } 7.64)\end{array}$ & $\begin{array}{c}10.84(7.20 \\
\text { to } 14.48)\end{array}$ & $\begin{array}{c}-8.56(-13.28 \\
\text { to }-3.84)\end{array}$ & $\begin{array}{c}-1.39(-5.67 \\
\text { to } 2.89)\end{array}$ & $\begin{array}{l}7.17(3.72 \\
\text { to } 10.62)\end{array}$ \\
\hline $\operatorname{NWC}(0-20)$ & $16.46(2.62)$ & $13.92(3.07)$ & $16.22(2.11)$ & $13.93(2.43)$ & $\begin{array}{c}2.54(0.86 \\
\text { to } 4.22)\end{array}$ & $\begin{array}{l}0.24(-1.00 \\
\text { to } 1.48)\end{array}$ & $\begin{array}{c}2.53(1.32 \\
\text { to } 3.74)\end{array}$ & $\begin{array}{c}-2.30(-4.06 \\
\text { to }-0.54)\end{array}$ & $\begin{array}{c}0.01(-1.82 \\
\text { to } 1.80)\end{array}$ & $\begin{array}{c}2.29(0.98 \\
\text { to } 3.60)\end{array}$ \\
\hline PPI $(0$ - 5) & $1.30(1.30)$ & $1.69(1.44)$ & $2.30(1.11)$ & $2.19(1.04)$ & $\begin{array}{c}-0.39(-1.21 \\
\text { to }-0.43)\end{array}$ & $\begin{array}{c}-1.00(-1.62 \\
\text { to }-0.38)\end{array}$ & $\begin{array}{c}-0.89(-1.47 \\
\text { to }-0.31)\end{array}$ & $\begin{array}{c}-0.61(-1.48 \\
\text { to } 0.26)\end{array}$ & $\begin{array}{l}-0.50(-1.31 \\
\text { to } 0.31)\end{array}$ & $\begin{array}{l}0.11(-0.50 \\
\text { to } 0.72)\end{array}$ \\
\hline \multicolumn{11}{|l|}{$\begin{array}{l}\text { Biological } \\
\text { Factor }\end{array}$} \\
\hline $\begin{array}{l}\text { Disability } \\
(0-24)\end{array}$ & $12.58(1.30)$ & $10.46(1.44)$ & $11.52(1.11)$ & $9.74(1.04)$ & $\begin{array}{l}2.12(1.30 \\
\text { to } 2.94)\end{array}$ & $\begin{array}{l}1.06(0.44 \\
\text { to } 1.68)\end{array}$ & $\begin{array}{c}2.84(2.26 \\
\text { to } 3.42)\end{array}$ & $\begin{array}{l}-1.06(-1.93 \\
\text { to }-0.19)\end{array}$ & $\begin{array}{l}0.72(-0.09 \\
\text { to } 1.53)\end{array}$ & $\begin{array}{l}1.78(1.17 \\
\text { to } 2.39)\end{array}$ \\
\hline \multicolumn{11}{|l|}{$\begin{array}{l}\text { Psychosocial } \\
\text { Factors }\end{array}$} \\
\hline $\begin{array}{l}\text { Depression } \\
(0-63)\end{array}$ & $21.13(10.12)$ & $14.54(8.34)$ & $17.26(9.53)$ & $14.44(10.17)$ & $\begin{array}{c}6.59(0.51 \\
\text { to } 12.67)\end{array}$ & $\begin{array}{l}3.87(-1.09 \\
\text { to } 8.83)\end{array}$ & $\begin{array}{l}6.69(1.90 \\
\text { to } 11.48)\end{array}$ & $\begin{array}{c}-2.72(-9.16 \\
\text { to } 3.72)\end{array}$ & $\begin{array}{l}0.10(-6.48 \\
\text { to } 6.68)\end{array}$ & $\begin{array}{l}2.82(-4.00 \\
\text { to } 9.64)\end{array}$ \\
\hline \multicolumn{11}{|l|}{$\begin{array}{l}\text { Pain beliefs } \\
\quad(0-4)\end{array}$} \\
\hline Pain control & $2.03(1.17)$ & $2.06(1.25)$ & $2.13(1.14)$ & $2.24(1.15)$ & $\begin{array}{c}-0.03(-0.76 \\
\text { to } 0.70)\end{array}$ & $\begin{array}{c}-0.10(-0.68 \\
\text { to } 0.48)\end{array}$ & $\begin{array}{l}-0.21(-0.76 \\
\text { to } 0.34)\end{array}$ & $\begin{array}{c}-0.07(-0.90 \\
\text { to } 0.76)\end{array}$ & $\begin{array}{c}-0.18(-0.99 \\
\text { to } 0.63)\end{array}$ & $\begin{array}{c}-0.11(-0.76 \\
\quad \text { to } 0.54)\end{array}$ \\
\hline Emotion & $2.48(1.36)$ & $2.44(1.37)$ & $2.68(1.52)$ & $2.11(1.36)$ & $\begin{array}{l}0.04(-0.80 \\
\text { to } 0.88)\end{array}$ & $\begin{array}{l}-0.20(-0.90 \\
\text { to } 0.50)\end{array}$ & $\begin{array}{l}0.37(-0.27 \\
\text { to } 1.01)\end{array}$ & $\begin{array}{l}-0.24(-1.28 \\
\text { to } 0.80)\end{array}$ & $\begin{array}{c}0.33(-0.60 \\
\text { to } 1.26)\end{array}$ & $\begin{array}{l}0.57(-0.25 \\
\text { to } 1.39)\end{array}$ \\
\hline Solicitude & $2.09(1.4)$ & $1.66(1.47)$ & $2.12(1.46)$ & $1.67(1.17)$ & $\begin{array}{l}0.43(-0.45 \\
\text { to } 1.31)\end{array}$ & $\begin{array}{l}-0.03(-0.74 \\
\text { to } 0.68)\end{array}$ & $\begin{array}{l}0.42(-0.21 \\
\quad \text { to } 1.05)\end{array}$ & $\begin{array}{l}-0.46(-1.49 \\
\text { to } 0.57)\end{array}$ & $\begin{array}{l}-0.01(-0.88 \\
\text { to } 0.86)\end{array}$ & $\begin{array}{l}0.45(-0.30 \\
\text { to } 1.20)\end{array}$ \\
\hline Harm & $2.69(0.94)$ & $2.43(1.4)$ & $2.42(1.19)$ & $2.16(0.96)$ & $\begin{array}{l}0.26(-0.39 \\
\text { to } 0.91)\end{array}$ & $\begin{array}{l}0.27(-0.24 \\
\text { to } 0.78)\end{array}$ & $\begin{array}{c}0.53(0.08 \\
\text { to } 0.98)\end{array}$ & $\begin{array}{l}0.01(-0.88 \\
\text { to } 0.90)\end{array}$ & $\begin{array}{l}0.27(-0.49 \\
\text { to } 1.03)\end{array}$ & $\begin{array}{l}0.26(-0.35 \\
\text { to } 0.87)\end{array}$ \\
\hline Disability & $3.12(0.98)$ & $2.64(1.24)$ & $3.13(1.12)$ & $2.77(1.27)$ & $\begin{array}{l}0.48(-0.16 \\
\text { to } 1.12)\end{array}$ & $\begin{array}{c}-0.01(-0.52 \\
\text { to } 0.50)\end{array}$ & $\begin{array}{l}0.35(-0.16 \\
\text { to } 0.86)\end{array}$ & $\begin{array}{c}-0.49(-1.31 \\
\text { to } 0.33)\end{array}$ & $\begin{array}{c}-0.13(-0.99 \\
\text { to } 0.73)\end{array}$ & $\begin{array}{c}0.36(-0.33 \\
\text { to } 1.05)\end{array}$ \\
\hline $\begin{array}{l}\text { Medical } \\
\text { cure }\end{array}$ & $2.93(0.97)$ & $2.91(0.80)$ & $3.15(0.89)$ & $2.70(1.16)$ & $\begin{array}{l}0.02(-0.56 \\
\text { to } 0.60)\end{array}$ & $\begin{array}{l}-0.22(-0.69 \\
\text { to } 0.25)\end{array}$ & $\begin{array}{l}0.23(-0.26 \\
\text { to } 0.72)\end{array}$ & $\begin{array}{l}-0.24(-0.85 \\
\text { to } 0.37)\end{array}$ & $\begin{array}{l}0.21(-0.51 \\
\quad \text { to } 0.93)\end{array}$ & $\begin{array}{c}0.45(-0.15 \\
\text { to } 1.05)\end{array}$ \\
\hline Medication & $2.17(1.18)$ & $2.54(1.32)$ & $1.96(1.26)$ & $2.35(1.17)$ & $\begin{array}{c}-0.37(-1.12 \\
\text { to } 0.38)\end{array}$ & $\begin{array}{l}0.21(-0.39 \\
\text { to } 0.81)\end{array}$ & $\begin{array}{c}-0.18(-0.74 \\
\text { to } 0.38)\end{array}$ & $\begin{array}{l}0.58(-0.32 \\
\text { to } 1.48)\end{array}$ & $\begin{array}{l}0.19(-0.64 \\
\text { to } 1.02)\end{array}$ & $\begin{array}{c}-0.39(-1.08 \\
\text { to } 0.30)\end{array}$ \\
\hline
\end{tabular}

Values in bold presented $\mathrm{p}<0.05$. 
subgroups I and III to report greater functional impact (Table 2). The individuals of the subgroup IV achieved significantly lower physical disability scores in comparison to subgroup one $(\mathrm{p}<0.05)$.

2) Psychosocial Factors

a) Depression

The results for the depression variable are comparable to those regarding physical disability (Table 2). The BDI scores were significantly higher in subgroup I in comparison to the subgroups II and IV $(\mathrm{p}<0.05)$.

b) Pain Beliefs

The Pain beliefs were generally similar among the different subgroups (Table 2). The scores on the Disability and Medical Cure subscales were the highest among all the items of the SOPA-brief, revealing that the participants believed they were incapacitated by pain and, in their view, the cure was exclusively the responsibility of health care professionals. Only the belief in Harm differed between subgroups; the mean score in the group with predominantly sensory pain (subgroup four) remained close to the neutral point and was significantly lower than that in subgroup I $(\mathrm{p}<0.05)$. The Control, Emotion and Solicitude subscales demonstrated a tendency ranging from more adaptive to neutral. Conversely, the Medication subscale ranged from neutral to less adaptive.

3) Socio-demographics and clinical Factors

The socio-demographics and clinical data were not included in tables. Only gender and current work status explained the subgroups differences. The gender proportion varied significantly between the subgroups I (wo$\operatorname{man}=94 \%)$ and IV (woman $=70 \%)(p<0.05)$. Although the women proportion on subgroup four remained higher, the most of men were allocated in the subgroup IV. In relation to current work status, the majority of workers on subgroup II were on leave from labor activities $(69 \%)$ compared to other subgroups (range 30 to $37 \%)(\mathrm{p}<0.05)$. There were no significant differences between subgroups with regard to socio-demographic variables (i.e., age and marital status), socioeconomic variables (i.e., schooling, occupation, income and recaption of benefits) and clinical variables (i.e., medical diagnosis, occupational nexus, side of the body affected, time elapsed since the onset of symptoms).

\subsection{Subgroups Profile of Workers with WRMD}

The individuals in subgroups I and III exhibited pain of a sensory-affective nature and reported higher levels for all variables analyzed. Subgroup I had the highest mean scores. These groups were comparable in their negative beliefs regarding pain as incapacitating, causing physical harm and the cure of which is achieved exclu- sively through medical assistance. The two subgroups were also similar with regard to gender (Cluster 1: 94\% female; Cluster 3: $83 \%$ female), the use of analgesics (Cluster 1: 62\%; Cluster 3: 65\%) and work status (30\% of each subgroup was on leave from labor activities).

In subgroup II, there was no predominance among the subscales of the Br-MPQ. However, this group was similar to subgroups I and III in the moderate levels on the PRI, physical disability and negative beliefs regarding pain. On the other hand, the individuals in this subgroup were less depressed $(\mathrm{p}<0.05)$ and used fewer analgesics $(31 \%)$, although the majority was on leave from work $(69 \%)$.

The individuals who compose the subgroup IV showed predominantly sensory pain. This subgroup presented the lower PRI, physical disability and depression levels. The beliefs of the individuals in this group suggest a negative perception of pain as incapacitating and curable through medical assistance. The use of analgesics $(56 \%)$ and number of individuals on leave from work activities $(37 \%)$ were similar to values found in subgroups I and III. Despite the predominance of women $(70 \%)$, this subgroup had a significantly higher proportion of men in comparison with the other groups $(\mathrm{p}<$ $0.05)$.

\section{DISCUSSION}

The present study identified four subgroups of workers with WRMD from a sample made up of patients with different chronic health conditions. The results revealed that patients with moderate to strong chronic pain associated with the sensory and affective components had higher degrees of disability and depression. These findings are consistent with previous studies involving cluster analysis for patients with chronic pain $[18,31,32]$.

There were similarities between the profiles of the patients in subgroups I and III. However, pain profile of subgroup I achieved higher mean scores for all variables analyzed. The high values on the Evaluative subscale and Pain Assessment Index of the Br-MPQ may help explain these differences. The Evaluative subscale reflects judgments on the part of the patient with regard to his/her pain based on sensory and affective characteristics as well as past experiences. The Pain Assessment Index is based on an increasing order of intensity regarding the descriptors that qualify pain within each subclass [22]. A number of authors state that suffering does not have a single manifestation for all individuals or a single family, culture or period of history [33]. In other words, suffering depends on the meaning each individual gives to this experience and involves the time and space in which it occurs. Thus, it is possible that pain experiences among the patients in subgroup I were more traumatic, which would 
explain the greater severity of symptoms in this group.

Although they were significantly less depressed, the patients of subgroup II reported a similar functional impact to that reported in subgroups I and III. It is interesting to note that the majority of this group was on leave from labor activities. According to Silva [34], the workplace is recognized as a privileged location of social integration and identity construction. The loss of labor capacity, therefore, represents a break or discontinuity in the life of an individual. The inability to exercise the role of a worker may lead to a reversion of roles within the family and changes in lifestyle caused by financial problems, inactivity and dependence [34]. Although not measured in the present study, it is possible to approximate the loss of identity of workers on leave with the results described by Crook et al. [35], who report that inactivity and the loss of physical capacity may trigger a vicious cycle of functional limitations; this functional loss may exercise a strong influence over the perpetuation of physical disability and a failure to return to work.

Lower pain levels (affective dimension), physical disability and depression were associated with patients in subgroup IV. The emotional response of an individual to an aversive stimulus, such as pain, may change their perception and elicit autonomic responses related to pain that directly affect the individual's illness [36]. Denison et al. analyzed the profile of patients with chronic musculoskeletal pain and found that higher pain levels and degrees of disability were associated to negative emotional responses, such as fear of movement and catastrophization [37]. Conversely, individuals who are emotionally more stable seem to respond better to treatment for pain and, consequently, have a greater likelihood of returning to work [18].

Another characteristic of the patients in subgroup IV was the high proportion of men. In a hierarchically organized society, gender may have an impact on how different forms of pain are experienced and expressed [16]. Studies suggest that men and women differ with regard to the experience and perception of pain, as women have lower pain thresholds and tolerance [38]. While such differences may explain the variations in the functional levels in this group, they do not clarify why the majority of patients reported the use of analgesics. Smitherman [39] stress that, besides physiological factors, differences between genders are permeated with cultural influences. The authors argue that men tend to suppress signs of pain under certain circumstances, reflecting stoic behavior; consequently, their pain levels may be underestimated. Thus, the question regarding the use of analgesics remains: Do these patients not manifest pain and disability or are both masked by the use of medication?

Depression was an effective variable for differentiating patients within the subgroups. There has currently been a considerable increase in the number of studies investigating the association between pain and depression. Much of this interest may be attributed to the frequency with which patients with chronic pain suffer from depression $[10,18]$. From the biological point of view, a possible explanation for the strong association between these two factors is the hypothesis of a common pathogenic mechanism in which both are seen as physiologically concomitant because they either directly or indirectly use the neurotransmitters serotonin and norepinephrine $[40,41]$.

Despite this association, only subgroups I and III exhibited significant depressive symptoms. Two factors appear to mediate the relationship between pain and depression: the perception of patients regarding the effects of pain on their lives and the perception of their ability to exercise some control over their pain [10]. The factors described by Gatchel et al. [10] are comparable to the pain beliefs assessed in the present study. In other words, those who suffer from pain but continue believing that they can be functional and maintain some control over their pain are less likely to be depressed [15].

It is possible that beliefs exercised a fundamental role in the adaptation of the individuals with regard to the continuity of the pain. There is consensus in the literature regarding the mediating role of beliefs in the loss of function $[10,15]$. Thus, the fact that the patients maintained feelings regarding the importance of emotions and that pain is self-controlled may partially explain the moderate levels of pain, depression and disability among the participants.

\section{CONCLUSION}

The results support the presupposition that chronic pain is a complex, multi-factor experience, considering the different worker profiles that emerged from the biological and psychosocial variables. The relationships between the groups confirm other findings that suggest that the chronification process of pain and its functional consequences vary between individuals and are influenced by emotional factors, such as depression and beliefs regarding pain. The identification of subgroups of individuals based on psychosocial and behavioral factors associated with chronic pain provide information that is not evident at the individual level. Consequently, these results could contribute to the design of more effective treatment strategies for different subgroups of patients. In the field of worker health, this outcome is of considerable importance, as pain relief and the successful return to work are the main goals.

\section{ACKNOWLEDGEMENTS}

The authors would like to thank for the support of Conselho $\mathrm{Na}$ - 
cional de Desenvolvimento Científico e Tecnológico (CNPq-National Council for Scientific and Technological Support) and of Fundação de Amparo a Pesquisa de Minas Gerais (FAPEMIG_-Foundation for Research Fostering in Minas Gerais).

\section{REFERENCES}

[1] World Health Organization (2008) WHO treatment guideline on non-malignant pain in adults. WHO, Geneva, 14.

[2] Sá, K., Baptista, A.F., Matos, M.A. and Lessa, I. (2009) Prevalence of chronic pain and associated factors in the population of Salvador, Bahia. Revista de Saúde Pública, 43, 622-630. doi:10.1590/S0034-89102009005000032

[3] Kreling, M.C.G.D., Cruz, D.A.L.M. and Pimenta, C.A.M. (2006) Prevalence of chronic pain in adult workers. Revista Brasileira de Enfermagem, 59, 509-513. doi:10.1590/S0034-71672006000400007

[4] Gheldof, E.L., Vinck, J., Van den Bussche, E., et al. (2006) Pain and pain-related fear are associated with functional and social disability in an occupational setting: Evidence of mediation by pain-related fear. European Journal of Pain, 10, 513-525. doi:10.1016/j.ejpain.2005.07.005

[5] Turner, J.A., Franklin, G., Heagerty, P.J., et al. (2004) The association between pain and disability. Pain, 112, 307314. doi:10.1016/i.pain.2004.09.010

[6] Castro, M.M. and Daltro, C. (2009) Sleep patterns and symptoms of anxiety and depression in patients with chronic pain. Arquivos de Neuro-Psiquiatria, 67, 25-28. doi:10.1590/S0004-282X2009000100007

[7] McWilliams, L.A., Cox, B.J. and Enns, M.W. (2003) Mood and anxiety disorders associated with chronic pain: An examination in a nationally representative sample. Pain, 106, 127-133. doi:10.1016/S0304-3959(03)00301-4

[8] Ratzon, N.Z., Jarus, T. and Catz, A. (2007) The relationship between work function and low back pain history in occupationally active individuals. Disability and Rehabilitation, 29, 791-796. doi:10.1080/09638280600919681

[9] Mossey, J.M., Gallagher, R.M. and Tirumalasetti, F. (2000) The effects of pain and depression on physical functioning in elderly residents of a continuing care retirement community. Pain Medicine, 1, 340-350. doi:10.1046/j.1526-4637.2000.00040.x

[10] Gatchel, R.J., Peng, Y.B., Peters, M.L., et al. (2007) The biopsychosocial approach to chronic pain: Scientific advances and future directions. Psychological Bulletin, 133, 581-624. doi:10.1037/0033-2909.133.4.581

[11] Geertzen, J.H., Van Wilgen, C.P., Schrier, E., et al. (2006) Chronic pain in rehabilitation medicine. Disability and Rehabilitation, 28, 363-367. doi:10.1080/09638280500287437

[12] Sampaio, R.F., Mancini, M.C., Gonçalves, G.G.P., et al. (2005) Application of the international classification of functioning, disability and health (ICF) in physiotherapists clinical practice. Brazilian Journal of Physical Therapy, 9, $1-7$.

[13] Linton, S.J., Buer, N., Vlaeyen, J., et al. (2000) Are fear avoidance beliefs related to the inception of an episode of back pain? A prospective study. Psychology \& Health, 14, 1051-1059. doi:10.1080/08870440008407366

[14] Burns, J.W., Kubilus, A., Bruehl, S., et al. (2001) A fourth empirically derived cluster of chronic pain patients based on the Multidimensional Pain Inventory: Evidence for repression within the dysfunctional group. Journal of Consulting and Clinical Psychology, 69, 663-673. doi:10.1037/0022-006X.69.4.663

[15] Turk, D.C. and Okifuji, A. (2002) Psychological factors in chronic pain: Evolution and revolution. Journal Consulting and Clinical Psychology, 70, 678-690.

[16] Alcântara, M.A., Sampaio, R.F., Pereira, L.S.M., et al. (2010) Disability associated with pain-A clinical approximation of the mediating effect of belief and attitudes. Physiotherapy Theory and Practice, 26, 459-467. doi: $10.3109 / 09593980903580233$

[17] Turk, D.C. (2005) The potential of treatment matching for subgroups of patients with chronic pain: Lumping versus splitting. Clinical Journal of Pain, 21, 44-55. doi:10.1097/00002508-200501000-00006

[18] Corbière, M., Sullivan, M.J.L., Stanish, W.D., et al. (2007) Pain and depression in injured workers and their return to work: A longitudinal study. Canadian Journal of Behavioural Science, 39, 23-31. doi:10.1037/cjbs2007002

[19] Gironda, R.J. and Clark, M.E. (2008) Cluster analysis of the pain outcomes questionnaire. Pain Medicine, 9, 813823. doi:10.1111/j.1526-4637.2007.00397.x

[20] Von Korff, M. and Miglioretti, D.L. (2005) A prognostic approach to defining chronic pain. Pain, 117, 304-313. doi:10.1016/j.pain.2005.06.017

[21] Brazil Ministry of Social Welfare (2003) Normative No. 98.

http://www.prt21.mpt.gov.br/fepmat/inst normativa.htm

[22] Castro, C.E.S. (2001) Formulation linguistics pain: Linguistic value and clinical pain complaints. Revista Dor Pesquisa Clínica e Terapêutica, 3, 114-122.

[23] Grafton, K., Foster, N. and Wright, C. (2002) Evaluation of the test-retest reliability of the short-form McGill pain questionnaire. Physiotherapy, 88, 108. doi:10.1016/S0031-9406(05)60934-0

[24] Jensen, M.P., Strom, S.E., Turner, J.A., et al. (1992) Validity of the sickness impact profile Roland scale as a measure of dysfunction in chronic pain patients. Pain, 50, 157-162. doi:10.1016/0304-3959(92)90156-6

[25] Nusbaum, L., Natour, J., Ferraz, M.B., et al. (2001) Translation, adaptation and validation of the Roland-Morris questionnaire-Brazil Roland-Morris. Brazilian Journal of Medical and Biological Research, 34, 203-210. doi:10.1590/S0100-879X2001000200007

[26] Gorestein, C. and Andrade, L. (1998) Beck depression inventory: Psychometric properties of the Portuguese version. Rev Psi Clin, 25, 245-250.

[27] Pimenta, C.A. and Da Cruz Dde, A. (2006) Chronic pain beliefs: Validation of the survey of pain attitudes for the Portuguese language. Revista da Escola Enfermagem da USP, 40, 365-373.

[28] Mingoti, S.A. (2005) Analyze data using multivariate 
statistical methods: An applied approach. Federal University of Minas Gerais (UFMG), Belo Horizonte.

[29] Hair, J.F., Black, W.C., Babin, B.J., et al. (2009) Multivariate data analysis. 6th Edition, Prentice Hall, Upper Saddle River.

[30] Possoli, S. (1984) Multivariate analysis techniques for the assessment of the health status of the "counties" of State of Rio Grande do Sul, Brazil. Revista de Saúde Pública, 18, 288-300. doi:10.1590/S0034-89101984000400004

[31] Turk, D.C., Okifuji, A., Starz, T.W., et al. (1998) Differential responses by psychosocial subgroups of fibromyalgia syndrome patients to an interdisciplinary treatment. Arthritis Care \& Research, 11, 397-404. doi:10.1002/art.1790110511

[32] Mongini, F., Rota, E., Evangelista, A., et al. (2009) Personality profiles and subjective perception of pain in head pain patients. Pain, 144, 125-129. doi:10.1016/j.pain.2009.03.026

[33] Brant, L.C. and Minayo-Gomes, C. (2004) The transformation process of suffering into illness: From the birth of the clinic to the psychodynamic work. Ciência \& Saúde Coletiva, 9, 213-223. doi:10.1590/S1413-81232004000100021

[34] Silva, F.C.M., Sampaio, R.F., Mancini, M.C., et al. (2011) A qualitative study of workers with chronic pain in Brazil and its social consequences. Occupational Therapy International, 18, 85-95. doi:10.1002/oti.302

[35] Crook, J., Milner, R., Schultz, I.Z., et al. (2002) Determinants of occupational disability following a low back
Injury: A critical review of the literature. Occupational Therapy International, 12, 277-295. doi:10.1023/A:1020278708861

[36] Rainville, P., Bao, Q.V.H. and Chrétien, P. (2005) Painrelated emotions modulate experimental pain perception and autonomic responses. Pain, 118, 306-318. doi:10.1016/j.pain.2005.08.022

[37] Denison, E., Åsenlöf, P., Sandborgh, M., et al. (2007) Musculoskeletal pain in primary health care: Subgroups based on pain intensity, disability, self-efficacy, and fearavoidance variables. The Journal of Pain, 8, 67-74. doi:10.1016/j.jpain.2006.06.007

[38] Paller, C.J., Campbell, C.M., Edwards, R.R., et al. (2009) Sex-based differences in pain perception and treatment. Pain Medicine, 10, 289-299. doi:10.1111/j.1526-4637.2008.00558.x

[39] Smitherman, A.H. (2012) Psychological predictors of pain responsivity: Explaining race and sex differences. Ph.D. Thesis, University of Alabama, Tuscaloosa.

[40] Rentsch, D., Piguet, V., Cedraschi, C., et al. (2009) Chronic pain and depression: A return trip? Revue Medicale Suisse, 5, 1364-1369.

[41] Dersh,J., Polatin, P.B. and Gatchel, R.J. (2002) Chronic pain and psychopathology: Research findings and theoretical considerations. Psychosomatic Medicine, 64, 773786. doi:10.1097/01.PSY.0000024232.11538.54 